\title{
Bring me sunshine: EU drug companies make payments to doctors public
}

This Feature contains an error in the eighth paragraph (BMJ 2013;347:f4342, doi:10.1136/bmj.f4342), where Novo Nordisk is listed as one of the companies not subscribing to the UK trade body the Association of the British Pharmaceutical Industry (ABPI). Novo Nordisk is in fact a member of the ABPI as of
March 2013, and is also a member of the European Federation of Pharmaceutical Industries and Associations.

Cite this as: BMJ 2013;347:f4521

๑) BMJ Publishing Group Ltd 2013 